\title{
Knowledge on the guideline-recommended use of antiplatelet and anticoagulant therapy during dental extractions: a contemporary survey among Polish dentists
}

\author{
Tomasz Tokarek', Magdalena Homaj², Michał Zabojszcz³, Magdalena Dolecka-Ślusarczyk³, \\ Michał Szotek ${ }^{1}$, Karol Sabatowski ${ }^{1}$, Bartłomiej Loster ${ }^{4}$, Stanisław Bartuś1, Zbigniew Siudak ${ }^{3}$ \\ 1 Department of Cardiology and Cardiovascular Interventions, University Hospital, Kraków, Poland \\ 2 Private Dental Practice, Kraków, Poland \\ 3 Faculty of Medicine and Health Sciences, Jan Kochanowski University, Kielce, Poland \\ 4 Department of Orthodontics, Institute of Dentistry, Jagiellonian University Medical College, Kraków, Poland
}

\section{KEY WORDS}

bleeding, dental extraction, dual antiplatelet therapy, non-vitamin $\mathrm{K}$ antagonist oral anticoagulants

Correspondence to: Prof. Zbigniew Siudak, MD, PhD, Faculty of Medicine and Health Science, Jan Kochanowski University, ul. IX Wieków Kielc 19A, 25-317 Kielce, Poland, phone: +48413496911, email: zbigniew.siudak@gmail.com Received: July 10, 2020. Revision accepted: August 20, 2020. Published online: August 26, 2020. Kardiol Pol. 2020; 78 (11): 1122-1128 doi:10.33963/KP.15588

Copyright by the Author(s), 2020

\section{ABSTRACT}

BACKGROUND The number of dental patients requiring periodic or lifelong antiplatelet or anticoagulant therapy is constantly growing.

AIMS We aimed to determine the level of knowledge on antiplatelet and anticoagulant therapy among Polish dentists.

METHODS A self-designed online questionnaire was distributed among dentists to evaluate their knowledge on the use of antiplatelet and anticoagulant drugs in clinical dental practice.

RESULTS The study included 352 dentists. Patients requiring vitamin $\mathrm{K}$ antagonists were referred for a cardiac consultation by $64.52 \%, 57.29 \%$, and $58.55 \%$ of dentists with $<5,5-15$, and $>15$ years of experience, respectively $(P=0.003)$. A similar trend was observed for non-vitamin $\mathrm{K}$ antagonist oral anticoagulants among nonsurgical dentists. However, an equal percentage of surgical dentists (39.7\%) performed extraction with and without consultation, and they were more likely to perform extraction without consultation than nonsurgical dentists $(39.7 \%$ vs $27.8 \% ; P=0.01)$. Most surgical and nonsurgical dentists preferred to consult a cardiologist about dual antiplatelet therapy before an invasive procedure (56.9\% and $73.81 \%$, respectively; $P=0.03$ ). Extractions in patients on aspirin were accepted by $75.81 \%, 70.83 \%$, and $49.34 \%$ of dentists with $<5,5-15$, and $>15$ years of experience, respectively $(P=0.004)$, and by $79.31 \%$ of surgical and $57.14 \%$ of nonsurgical dentists $(P=0.003)$.

CONCLUSIONS Knowledge on antiplatelet and anticoagulant therapy in patients undergoing dental procedures is unsatisfactory among Polish dentists. Both therapies were discontinued before extractions more frequently than recommended in the guidelines, while extractions in patients on aspirin were common.

INTRODUCTION The number of dental patients requiring periodic or lifelong treatment with antiplatelet or anticoagulant agents has been increasing worldwide. ${ }^{1}$ Dual antiplatelet therapy (DAPT) with $\mathrm{P}_{12} \mathrm{Y}_{12}$ inhibitors in addition to aspirin is required in all patients after percutaneous coronary intervention. Moreover, there is a growing population of patients with clinical indications for anticoagulant therapy with vitamin K antagonists (VKAs) or non-VKA oral anticoagulants (NOACs). ${ }^{2-4}$ Most dental procedures are associated with a low risk of bleeding and self-limited blood loss that might be managed with local hemostatic agents. However, the use 


\section{WHAT'S NEW?}

With increased life expectancy, there has been an exponential growth in the population of dental patients requiring periodic or lifelong treatment with antiplatelet or anticoagulant drugs. Despite the widespread use of dual antiplatelet therapy and anticoagulants, data on the adherence of dentists to current recommendations are scarce. Our study suggests that Polish dentists have insufficient knowledge on antiplatelet and anticoagulant treatment of patients undergoing invasive dental procedures. Treatment with antiplatelets and oral anticoagulants was interrupted before dental extractions more often than recommended in the guidelines. On the other hand, dental extractions were common in patients taking aspirin. There is a continuous need for up-to-date knowledge on antiplatelet or anticoagulant therapy among Polish dentists.

of anticoagulants is linked with a higher risk of bleeding complications, especially when used in combination with common nonsteroidal anti-inflammatory drugs. ${ }^{5-10}$ Yet, discontinuation of these drugs might result in cardiovascular complications such as thrombosis or ischemic stroke. ${ }^{11,12}$ Therefore, it is crucial that dentists have sufficient knowledge on the management of these patients to avoid such complications in daily dental practice. Continuation of DAPT is associated with a low risk of bleeding complications after dental extractions. ${ }^{12}$ In addition, single antiplatelet therapy with aspirin seems to have no impact on bleeding risk, thus antiplatelet treatment should not be interrupted. ${ }^{12,13}$ In patients with high bleeding risk, both VKAs and NOACs should be discontinued. On the other hand, patients at increased risk of thrombosis might require a consultation with a cardiologist. ${ }^{12}$ In general, dental extractions can be safely performed without stopping the anticoagulant treatment by using hemostatic agents as prophylaxis or by omitting only one morning dose of a NOAC. ${ }^{14,15}$ Despite the widespread use of DAPT and anticoagulants, there are scarce data on the adherence of dentists to the current standard of care. ${ }^{1,16}$ Therefore, we conducted this study to determine the level of knowledge on antiplatelet and anticoagulant therapy among Polish dentists as well as the extent to which they adhere to current guidelines. Moreover, by identifying the possible areas that need improvement, we aimed to raise the awareness of the problem among healthcare providers in Poland.

METHODS A self-designed online questionnaire was administered to all registered members of the Polish Dental Association (approximately 3000 members) via email to evaluate their level of knowledge on the use of antiplatelet and anticoagulant treatment in clinical dental practice (Supplementary material). Questions were modeled according to the current guidelines of the European Society of Cardiology. ${ }^{3,17}$ The questionnaire included questions regarding the sociodemographic and clinical profile of respondents as well as their clinical decisions regarding DAPT and anticoagulant treatment in patients requiring dental extractions. There was no time limit for any of the questions. The survey was open for 1 month, and multiple attempts were made to promote it among dentists. A total of 352 dentists responded to the survey and were included in the study group. Respondents included surgical specialists, defined as dental surgeons and maxillofacial surgeons, as well as nonsurgical dentists. Experience was defined as years of clinical practice $(<5,5-15$, and $>15$ years).

Ethical concerns The study protocol was approved by the Bioethics Committee of Poznan University of Medical Sciences. The study was conducted in accordance with ethical principles for clinical research based on the Declaration of Helsinki with later amendments.

Statistical analysis Standard descriptive statistical calculations were used. The normal distribution of data was evaluated with the Shapiro-Wilk test. Categorical variables were presented as numbers and percentages. The $\mathrm{X}^{2}$ test for categorical variables was used for direct comparisons between groups. The level of statistical significance was set at a $P$ value of 0.05 or lower. All analyses were conducted with the STATISTICA version 13 software (StatSoft, Inc., Kraków, Poland).

RESULTS Of the 352 respondents included in the study, 182 (51.7\%) had over 15 years of experience in dentistry. A minority of respondents had surgical specialty, but nearly half of the participants were specialists in other specialties. Detailed distribution of respondents according to specialty and experience is presented in FIGURE 1. Regardless of experience, most respondents were more likely to consult a cardiologist before dental extraction in patients requiring VKA treatment (TABLE 1). Similar results were noted for surgical specialists regarding patients on NOAC therapy. However, an equal percentage of surgical dentists would perform extraction with and without consultation with a cardiologist (TABLE 1). On the other hand, dentists without surgical specialty preferred to consult a cardiologist before invasive procedures in patients receiving NOAC therapy. Regardless of the specialty, most dentists did not require the international normalized ratio (INR) value before dental extraction in patients on NOACs (TABlE 2). Surgical specialists accepted the INR value measured 24 hours before extraction, while most dentists without surgical specialty considered the results up to 48 hours before the procedure as reliable. These results show that many dentists made clinical 
TABLE 1 Dental extractions in patients on anticoagulant therapy

\begin{tabular}{|c|c|c|c|c|c|c|}
\hline Respondents & & Yes & $\begin{array}{l}\text { Yes, but with } \\
\text { the omission of } \\
\text { the morning drug dose }\end{array}$ & $\begin{array}{l}\text { No, I would } \\
\text { consult } \\
\text { a cardiologist }\end{array}$ & $\begin{array}{l}\text { No, I would refer to } \\
\text { another dentist }\end{array}$ & $P$ value \\
\hline \multicolumn{7}{|c|}{ Dental extraction on VKAs (warfarin, acenocoumarol) with INR in the therapeutic range } \\
\hline \multirow[t]{3}{*}{ Years of dental practice } & $<5$ & $19(30.7)$ & $2(3.2)$ & $40(64.5)$ & $1(1.6)$ & \multirow[t]{3}{*}{0.003} \\
\hline & $5-15$ & $36(37.5)$ & $2(2.1)$ & $55(57.3)$ & $3(3.1)$ & \\
\hline & $>15$ & $26(17.1)$ & $20(13.2)$ & $89(58.6)$ & $17(11.2)$ & \\
\hline \multirow[t]{2}{*}{ Any dental specialty } & Yes & $35(25.7)$ & $15(11)$ & $76(55.9)$ & $10(7.4)$ & \multirow[t]{2}{*}{0.3} \\
\hline & No & $46(26.4)$ & $9(5.2)$ & $108(62.1)$ & $11(6.3)$ & \\
\hline \multirow[t]{2}{*}{ Surgical specialty } & Yes & $18(31)$ & $6(10.3)$ & $34(58.6)$ & 0 & \multirow[t]{2}{*}{0.1} \\
\hline & No & $63(25)$ & $18(7.1)$ & $150(59.5)$ & $21(8.3)$ & \\
\hline \multicolumn{7}{|c|}{ Dental extraction on NOACs (dabigatran, rivaroxaban, apixaban) } \\
\hline \multirow[t]{3}{*}{ Years of dental practice } & $<5$ & $22(35.5)$ & $5(8.1)$ & $32(51.6)$ & $3(4.9)$ & \multirow[t]{3}{*}{0.3} \\
\hline & $5-15$ & $31(32.3)$ & $13(13.5)$ & $47(48.9)$ & $5(5.2)$ & \\
\hline & $>15$ & $40(26.3)$ & $26(17.1)$ & $71(46.7)$ & $15(9.9)$ & \\
\hline \multirow[t]{2}{*}{ Any dental specialty } & Yes & $42(30.9)$ & $23(16.9)$ & $61(44.9)$ & $10(7.4)$ & \multirow[t]{2}{*}{0.6} \\
\hline & No & $51(29.3)$ & $21(12.1)$ & $89(51.2)$ & $13(7.5)$ & \\
\hline \multirow[t]{2}{*}{ Surgical specialty } & Yes & $23(39.7)$ & $12(20.7)$ & $23(39.7)$ & 0 & \multirow[t]{2}{*}{0.01} \\
\hline & No & $70(27.8)$ & $32(12.7)$ & $127(50.4)$ & $23(9.1)$ & \\
\hline
\end{tabular}

Data are presented as the number (percentage) of respondents.

Abbreviations: INR, international normalized ratio; NOAC, non-vitamin K antagonist oral anticoagulant; VKA, vitamin K antagonist

A
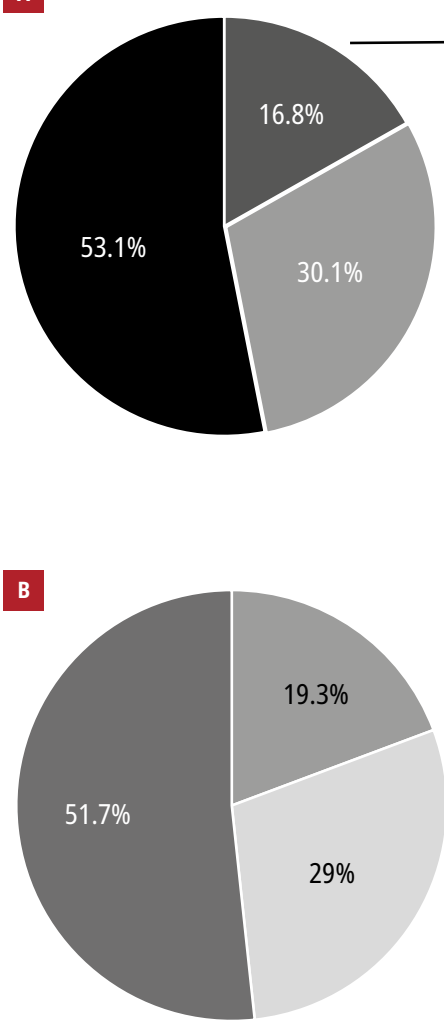

FIGURE 1 Distribution of the study group according to: A - dental specialty; B - experience (years of clinical practice)

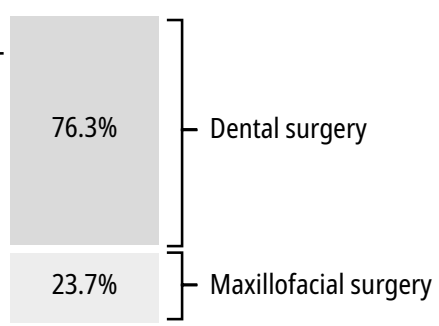

- Surgical specialty

- Nonsurgical specialty

- During specialty training

$$
\begin{aligned}
& <5 \text { years } \\
& 5-15 \text { years } \\
& \square>15 \text { years }
\end{aligned}
$$

decisions on the basis of INR values that were invalid or outdated. Furthermore, many respondents unnecessarily required the INR value before invasive procedures in patients on NOACs (TABlE 3). No differences in the level of knowledge on anticoagulant therapy were noted between dentists during training and specialists. Moreover, experience had no impact on routine INR testing before the procedure (TABLES 2 and 3). Similar results were observed regarding patients on DAPT. Both surgical and nonsurgical dentists were more likely to refer patients to a cardiologist prior to invasive procedures (TABLE 4). However, a minority of respondents considered dental extraction to be safe in patients on DAPT. Dental extraction in patients taking aspirin was considered safe regardless of experience. Both surgical and nonsurgical specialists were likely to perform tooth extraction in patients on aspirin (TABLE 5).

DISCUSSION Our study demonstrated that Polish dentists more often discontinue antiplatelet or oral anticoagulant therapy in their patients prior to dental extractions than it is recommended in the guidelines. Moreover, we noted major differences among dentists in the use of antiplatelet and anticoagulant therapy depending on specialty and experience defined as years of 
TABLE 2 Knowledge on the importance of international normalized ratio measurement before dental extraction in patients on oral anticoagulant therapy

\begin{tabular}{|c|c|c|c|c|}
\hline \multirow[t]{2}{*}{ Respondents } & & \multicolumn{2}{|c|}{$\begin{array}{l}\text { Do you order the INR test before dental extraction in } \\
\text { a patient receiving a NOAC? }\end{array}$} & \multirow[t]{2}{*}{$P$ value } \\
\hline & & Yes & No & \\
\hline \multirow[t]{3}{*}{ Years of dental practice } & $<5$ & $28(45.2)$ & $34(54.8)$ & \multirow[t]{3}{*}{0.5} \\
\hline & $5-15$ & $36(37.5)$ & $60(62.5)$ & \\
\hline & $>15$ & $68(44.7)$ & $84(55.3)$ & \\
\hline \multirow[t]{2}{*}{ Any dental specialty } & Yes & $54(39.7)$ & $82(60.3)$ & \multirow[t]{2}{*}{0.4} \\
\hline & No & 78 (44.8) & $96(55.2)$ & \\
\hline \multirow[t]{2}{*}{ Surgical specialty } & Yes & $16(27.6)$ & $42(72.4)$ & \multirow[t]{2}{*}{0.01} \\
\hline & No & $116(46)$ & $136(53.9)$ & \\
\hline
\end{tabular}

Data are presented as the number (percentage) of respondents.

Abbreviations: see TABLE 1

TABLE 3 Time range for reliability of the international normalized ratio value before extraction in patients receiving vitamin $\mathrm{K}$ antagonists

\begin{tabular}{|c|c|c|c|c|c|c|}
\hline Respondents & & Till 48 hours & Till 24 hours & Till 5 days & Till 7 days & $P$ value \\
\hline \multirow[t]{3}{*}{ Years of dental practice } & $<5$ & $25(40.3)$ & $29(46.8)$ & $5(8.1)$ & $3(4.8)$ & \multirow[t]{3}{*}{0.4} \\
\hline & $5-15$ & $41(42.7)$ & 41 (42.7) & $7(7.3)$ & $7(7.3)$ & \\
\hline & $>15$ & $52(34.2)$ & $63(41.5)$ & $23(15.1)$ & $14(9.2)$ & \\
\hline \multirow[t]{2}{*}{ Any dental specialty } & Yes & $51(37.5)$ & $61(44.9)$ & $16(11.8)$ & $8(5.9)$ & \multirow[t]{2}{*}{0.7} \\
\hline & No & $67(38.5)$ & $72(41.4)$ & $19(10.9)$ & $16(9.2)$ & \\
\hline \multirow[t]{2}{*}{ Surgical specialty } & Yes & $16(27.6)$ & $35(60.3)$ & $4(6.9)$ & $3(0.9)$ & \multirow[t]{2}{*}{0.03} \\
\hline & No & $102(40.5)$ & $98(38.9)$ & $31(12.3)$ & $21(8.3)$ & \\
\hline
\end{tabular}

Data are presented as the number (percentage) of respondents.

TABLE 4 Dental extractions in patients on dual antiplatelet therapy (aspirin and clopidogrel or prasugrel or ticagrelor)

\begin{tabular}{|c|c|c|c|c|c|c|}
\hline \multicolumn{2}{|l|}{ Respondents } & Yes & $\begin{array}{l}\text { Yes, but with } \\
\text { cessation of one } \\
\text { antiplatelet drug }\end{array}$ & $\begin{array}{l}\text { Yes, but with } \\
\text { cessation of both } \\
\text { antiplatelet drugs }\end{array}$ & $\begin{array}{l}\text { No, I would } \\
\text { consult } \\
\text { a cardiologist }\end{array}$ & $P$ value \\
\hline \multirow{3}{*}{$\begin{array}{l}\text { Years of } \\
\text { dental } \\
\text { practice }\end{array}$} & $<5$ & $14(22.6)$ & $3(4.8)$ & $1(1.6)$ & $44(70.9)$ & \multirow[t]{3}{*}{0.2} \\
\hline & $5-15$ & $16(16.7)$ & $8(8.3)$ & $6(6.3)$ & $66(68.8)$ & \\
\hline & $>15$ & $17(11.2)$ & $16(10.5)$ & $10(6.6)$ & 109 (71.7) & \\
\hline \multirow{2}{*}{$\begin{array}{l}\text { Any dental } \\
\text { specialty }\end{array}$} & Yes & 19 (13.9) & $13(9.6)$ & $10(7.4)$ & 94 (69.1) & \multirow[t]{2}{*}{0.6} \\
\hline & No & $28(16.1)$ & $14(8.1)$ & $7(4)$ & $125(71.8)$ & \\
\hline \multirow{2}{*}{$\begin{array}{l}\text { Surgical } \\
\text { specialty }\end{array}$} & Yes & $15(25.9)$ & $5(8.6)$ & $5(8.6)$ & $33(56.9)$ & \multirow[t]{2}{*}{0.03} \\
\hline & No & $32(12.7)$ & $22(8.7)$ & $12(4.8)$ & $186(73.8)$ & \\
\hline
\end{tabular}

Data are presented as the number (percentage) of respondents.

clinical practice. Patients requiring treatment with VKAs were more often referred by dentists to a cardiologist, regardless of experience. A similar trend for NOAC therapy was observed among nonsurgical dentists. However, an equal percentage of surgical dentists would perform extraction with and without consultation with a cardiologist. Regardless of the specialty, most dentists preferred to consult a cardiologist before an invasive procedure in patients on DAPT. In contrast, dental extractions on aspirin treatment were considered safe by most practitioners, 
TABLE 5 Dental extractions in patients on aspirin

\begin{tabular}{|c|c|c|c|c|c|}
\hline Respondents & & Yes & $\begin{array}{l}\text { Yes, but with } \\
\text { cessation of aspirin }\end{array}$ & $\begin{array}{l}\text { No, I would consult } \\
\text { a cardiologist }\end{array}$ & $P$ value \\
\hline \multirow{3}{*}{$\begin{array}{l}\text { Years of dental } \\
\text { practice }\end{array}$} & $<5$ & $47(75.8)$ & $9(14.5)$ & $6(9.7)$ & \multirow[t]{3}{*}{0.004} \\
\hline & $5-15$ & $68(70.8)$ & $18(18.8)$ & $10(10.4)$ & \\
\hline & $>15$ & $75(49.3)$ & $58(38.2)$ & $19(12.5)$ & \\
\hline \multirow{2}{*}{$\begin{array}{l}\text { Any dental } \\
\text { specialty }\end{array}$} & Yes & $82(60.3)$ & $40(29.4)$ & $14(10.3)$ & \multirow[t]{2}{*}{0.7} \\
\hline & No & $108(62.1)$ & $45(25.9)$ & $21(12.1)$ & \\
\hline \multirow[t]{2}{*}{ Surgical specialty } & Yes & $46(79.3)$ & $11(18.9)$ & $1(1.7)$ & \multirow[t]{2}{*}{0.003} \\
\hline & No & $144(57.1)$ & $74(29.4)$ & $34(13.5)$ & \\
\hline
\end{tabular}

Data are presented as the number (percentage) of respondents.

regardless of the specialty and experience. A referral to a cardiologist might sometimes be beneficial (eg, in cases of tooth extraction within 2-4 weeks after percutaneous coronary intervention); therefore, its value should not be underestimated.

Our major findings are in line with most contemporary studies. Recently, Ringel and Maas ${ }^{18}$ reported that tooth extractions in patients on aspirin and VKAs were performed by $77.4 \%$ and $27.6 \%$ of dentists, respectively. Furthermore, $29.5 \%$ of dentists accepted the INR values above and below the therapeutic range ( $\leq 1.5$ or $\geq 3.5$ ). Over $90 \%$ of respondents accepted INR values that were too old to be clinically reliable. ${ }^{18} \mathrm{An}$ other study confirmed that dentists had limited knowledge on antiplatelet drugs and the consequences of therapy discontinuation. ${ }^{19,20}$ A recent survey demonstrated that $15.9 \%$ of respondents systematically discontinued VKAs before invasive oral procedures, $25.3 \%$ administered heparin instead, and only $16.5 \%$ did not discontinue VKA therapy. ${ }^{21}$ Only $11.2 \%$ of practitioners were familiar with the guidelines, mostly young dentists and women. An Irish study revealed that $25 \%$ of respondents did not measure the INR before dental extractions in patients receiving VKAs. ${ }^{22}$ Furthermore, in a survey among Danish dentists, $50 \%$ of participants were not familiar with the INR test. ${ }^{23}$ A study conducted in India showed that only $7.1 \%$ of dentists from university centers were familiar with NOACs. ${ }^{24}$ Finally, a recent study, conducted 11 years after the first French guidelines on anticoagulant therapy in oral surgery, showed that $95 \%$ of practitioners performed invasive procedures in patients treated with VKAs (mostly low risk of bleeding). ${ }^{25}$ Participants showed a high level of knowledge about VKA treatment, INR monitoring, and local hemostatic techniques. ${ }^{25}$ A substantial improvement in the level of knowledge was noted in comparison with a previous study. ${ }^{21,25}$

Although Polish dentists showed suboptimal knowledge about the importance of INR monitoring in patients on VKAs and NOACs, it was relatively better than in other countries. Therefore, it is important to allow time for the implementation of guidelines and provide educational courses for dentists in primary care. Knowledge on NOAC treatment was also shown to improve, with up to $87 \%$ of practitioners reporting familiarity with these drugs. It was revealed that $62.9 \%$ of respondents did not modify the treatment before invasive oral procedures, $70.8 \%$ did not evaluate coagulation parameters, and only $13.9 \%$ measured the INR. ${ }^{25}$ The level of knowledge differed among Polish dentists depending on the type of treatment, although major gaps were revealed both for antiplatelets and anticoagulants. Many dentists may not be familiar with the specific characteristics of these drugs, which greatly impairs the decision-making process.

Several randomized trials demonstrated that discontinuation of DAPT increases the risk of stent thrombosis, which may occur either as an early or late complication. 2,26,27 Stent thrombus is associated with a high incidence of myocardial infarction and a short-term mortality rate of up to $50 \%$ to $70 \%{ }^{2,17}$ Moreover, NOACs are crucial for stroke prevention in patients with atrial fibrillation. ${ }^{18-21}$ Withdrawal of anticoagulant therapy could lead to ischemic stroke, potentially resulting in disability or death. Therefore, continuation of both DAPT and NOACs is crucial for the prevention of major adverse cardiac events, ${ }^{26-29}$ although it is associated with the risk of bleeding complications. The bleeding risk is possibly the most important factor to be taken into account by dentists when considering discontinuation of one or both therapies. Careful patient selection is essential for preventing complications. Basic classification of dental procedures into those with low and high bleeding risk might be helpful. ${ }^{26-29} \mathrm{An}$ individual approach to patients is necessary, with the assessment not only of local bleeding risk related to a dental procedure but also of thrombotic and bleeding risk related to cardiovascular disease. ${ }^{30}$ Most dental interventions might be safely performed without modification of antiplatelet 
or anticoagulant therapy. In our study, surgical dentists were more likely to make such decisions on their own than those without surgical specialty. However, adherence to the current standards of care among Polish dentists is still low, and the knowledge on the management of patients treated with antiplatelet or anticoagulant drugs remains suboptimal. As the number of patients requiring such treatment is expected to grow due to increased life expectancy, it is crucial to improve current knowledge and awareness among practicing dentists.

Limitations Our results should be considered in light of several limitations. Most importantly, the size of the study group was relatively low. Even though the online questionnaire was easy to use, quick to complete, and was actively promoted among the members of the Polish Dental Association, the response rate was only $12 \%$. It is possible that dentists who did not complete the survey have poorer knowledge on the subject, which may have biased our results. Therefore, our study may not adequately reflect the actual level of knowledge among Polish dentists. However, the sample was similar to that in previous studies from other countries, such as Germany or Spain. Moreover, there is a limited number of patients treated with DAPT and VKAs or NOACs per each dentist. We did not evaluate dentists' experience by the number of patients treated (number of extractions) or treatment outcomes. The definition of experience adopted in our study as years of clinical practice might not fully reflect the actual clinical experience.

Conclusions The management of patients receiving antiplatelet and anticoagulant drugs and undergoing dental procedures seems to be unsatisfactory in Poland. Polish dentists show suboptimal adherence to guidelines, and both therapies were discontinued prior to dental extractions more frequently than recommended. On the other hand, dental extractions were common in patients on aspirin. Ongoing efforts should be made to propagate up-to-date knowledge on antiplatelet and anticoagulant therapy among Polish dentists in the form of training courses or webinars. Multidisciplinary task force groups including both cardiologists and dentists should be created to establish an agenda and oversee the implementation of measures as part of quality control.

\section{SUPPLEMENTARY MATERIAL}

Supplementary material is available at www.mp.pl/kardiologiapolska.

\section{ARTICLE INFORMATION}

\section{CONFLICT OF INTEREST None declared.}

OPEN ACCESS This is an Open Access article distributed under the terms of the Creative Commons Attribution-NonCommercial-NoDerivatives 4.0 International License (CC BY-NC-ND 4.0), allowing third parties to download articles and share them with others, provided the original work is properly cited, not changed in any way, distributed under the same license, and used for noncommercial purposes only. For commercial use, please contact the journal office at kardiologiapolska@ptkardio.pl.

HOW TO CITE Tokarek T, Homaj M, Zabojszcz M, et al. Knowledge on the guideline-recommended use of antiplatelet and anticoagulant therapy during dental extractions: a contemporary survey among Polish dentists. Kardiol Pol. 2020; 78: 1122-1128. doi:10.33963/KP.15588

\section{REFERENCES}

1 Population Division. Department of Economic and Social Affairs. United Nations. Revision of World Population Prospects. https://esa.un.org/unpd/wpp/. Accessed April 3, 2020.

2 Neumann FJ, Sousa-Uva M, Ahlsson A, et al; ESC Scientific Document Group. 2018 ESC/EACTS Guidelines on myocardial revascularization. Eur Heart J. 2019; 40: 87-165.

3 Kirchof P, Benussi S, Kotecha D, et al. 2016 ESC Guidelines for the management of atrial fibrillation developed in collaboration with EACTS. Eur Heart J. 2016; 37: 2893-2962.

4 Heidbuchel $H$, Verhamme P, Alings M, et al. European Heart Rhythm Association Practical Guide on the use of new oral anticoagulants in patients with non-valvular atrial fibrillation. Europace. 2013; 15: 625-651.

5 Chee YL, Crawford JC, Watson HG, et al. Guidelines on the assessment of bleeding risk prior to surgery or invasive procedures. British Committee for Standards in Haematology. Br J Haematol. 2008; 140: 496-504.

6 Fleisher LA, Fleischmann KE, Auerbach AD, et al. 2014 ACC/AHA guideline on perioperative cardiovascular evaluation and management of patients undergoing noncardiac surgery: a report of the American College of Cardiology/American Heart Association Task Force on practice guidelines. J Am Coll Cardiol. 2014; 64: 77-137.

7 Siller-Matula JM, Petre A, Delle-Karth G, et al. Impact of preoperative use of $P 2 Y 12$ receptor inhibitors on clinical outcomes in cardiac and non-cardiac surgery: a systematic review and meta-analysis. Eur Heart J Acute Cardiovasc Care. 2017; 6: 753-770.

8 Cannon PD, Dharmar VT. Minor oral surgical procedures in patients on oral anticoagulants - a controlled study. Aust Dent J. 2003; 48: 115-118.

9 Kämmerer PW, Frerich B, Liese J, et al. Oral surgery during therapy with anticoagulants - a systematic review. Clin Oral Investig. 2015; 19: 171-180.

10 Shi Q, Xu J, Zhang T, et al. Post-operative bleeding risk in dental surgery for patients on oral anticoagulant therapy: a meta-analysis of observational studies. Front Pharmacol. 2017; 8: 58.

11 Burger W, Chemnitius JM, KneissI GD, et al. Low-dose aspirin for secondary cardiovascular prevention - cardiovascular risks after its perioperative withdrawal -versus bleeding risks with its continuation - review and meta-analysis. J Internal Med. 2005; 257: 399-414.

12 Pruszczyk P, Ciurzyński M, Opolski G, et al. Dental cardio common position for dealing anticoagulation in patients undergoing dental procedures [in Polish]. Kardiol Pol. 2016; 74: 87-98.

13 Zabojszcz M, Malinowski KP, Janion-Sadowska A, et al. Safety of dental extractions in patients on dual antiplatelet therapy - a meta-analysis. Postepy Kardiol Interwencyjnej. 2019; 15: 68-73.

14 Mauprivez C, Khonsari RH, Razouk 0, et al. Management of dental extraction in patients undergoing anticoagulant oral direct treatment: a pilot study. Oral Surg Oral Med Oral Pathol Oral Radiol. 2016; 122: 146-155.

15 Miclotte I, Vanhaverbeke M, Agbaje J0, et al. Pragmatic approach to manage new oral anticoagulants in patients undergoing dental extractions: a prospective case-control study. Clin Oral Investig. 2017; 21: 2183-2188.

16 Dudek D, Siudak Z, Grygier M, et al. Interventional cardiology procedures in Poland in 2018. Summary report of the Association of Cardiovascular Interventions of the Polish Cardiac Society (AISN PTK) and Jagiellonian University Medical College. Postepy Kardiol Interwencyjnej. 2019; 15: 391-393.

17 Valgimigli M, Bueno H, Byrne RA, et al. 2017 ESC focused update on dual antiplatelet therapy in coronary artery disease developed in collaboration with EACTS. Eur Heart J. 2018; 39: 213-260.

18 Ringel R, Maas R. Dental procedures in patients treated with antiplatelet or oral anticoagulation therapy - an anonymous survey. Gerodontology. 2016; 33: 447-452.

19 Can MM, Biteker M, Babur G, et al. Knowledge, attitude and perception of antiplatelet therapy among dentists in Central Eastern Turkey. World J Cardiol. 2012; 4: 226-230.

20 Lozano I, Martín D, Torres F, et al. Knowledge of coronary stents, thrombosis and dual antiplatelet therapy among Spanish dentists. Rev Esp Cardiol. 2009; 62: 153-157.

21 Massot M, Clipet F, Alno N, et al. Étude épidémiologique sur les extractions dentaires chez les patients sous AVK en Ille-et-Vilaine. Med Buccale Chir Buccale Hors Série. 2009; 15: 29-37.

22 Murphy J, Twohig E, Mcwilliams SR. Dentists' approach to patients on anti-platelet agents and warfarin: a survey of practice. J Ir Dent Assoc. 2010; 56: 28-31. 
23 Van Diermen DE, Bruers J], Hoogstraten J, et al. Treating dental patients who use oral antithrombotic medication: a survey of dentists in the Netherlands. J Am Dent Assoc. 2011; 142: 1376-1382.

24 Chinnaswami R, Bagadia RK, Mohan A, et al. Dentists' knowledge, attitude and practice in treating patients taking oral antithrombotic medications - a survey. J Clin Diagn Res. 2017; 11: 88-91.

25 Radoï L, Hajage D, Giboin C, et al. Perioperative management of oral anticoagulated patients undergoing an oral, implant, or periodontal procedure: a survey of practices of members of two dental scientific societies, the PRADICO study. Clin Oral Investig. 2019; 23: 4311-4323.

26 Furie KL, Goldstein LB, Albers GW, et al. Oral antithrombotic agents for the prevention of stroke in nonvalvular atrial fibrillation: a science advisory for healthcare professionals from the American Heart Association/American Stroke Association. Stroke. 2012; 43: 3442-3453.

27 Fortier K, Shroff D, Reebye UN. Review: an overview and analysis of novel oral anticoagulants and their dental implications. Gerodontology 2018; 35: 78-86.

28 Ciurus T, Sobczak S, Cichocka-Radwan A, et al. New oral anticoagulants a practical guide. Kardiochir Torakochirurgia Pol. 2015; 12: 111-118.

29 Pruszczyk P, Tomaszuk-Kazberuk A, Słowik A, et al. Management of bleeding or urgent interventions in patients treated with direct oral anticoagulants: 2017 recommendations for Poland. Pol Arch Intern Med. 2017; 127: 343-351.

30 Douketis JD, Darvish-Kazem S, Spencer N, Tafur A. Perioperative management of patients who are receiving antiplatelet therapy: a case-based, evidence-informed approach. Pol Arch Intern Med. 2018; 128: 771-778. 